\title{
Анализ современных тенденций развития мирового рынка платежных карт
}

\section{Георгий Хетагуров}

Северо-Кавказский горно-металлургический институт, г. Владикавказ, Россия

\author{
Информация о статье \\ Поступила в редакцию: \\ 29.04.2018 \\ Принята \\ к опубликованию: \\ 28.05.2018
}

УДК 336.71

JEL E42

\section{Ключевые слова:}

мировой рынок платежных карт, карточная платежная система, индустрия платежных карт, международная платежная система, локальная платежная система, платежная инфраструктура

\section{Keywords:}

world market of payment cards, card payment system, industry of payment cards, international payment system, local payment system, payment infrastructure

\begin{abstract}
Аннотация
В статье исследуются основные тенденции развития современного глобального рынка карточных платежных систем. В частности, рассматриваются характер и динамика распределения рыночных долей международных и локальных платежных систем в разрезе различных потребительских и географических сегментов, выявляются основные стратегические направления развития платежных систем, прогнозируются базовые параметры карточной индустрии на ближайшие годы.
\end{abstract}

Analysis of Current Trends in the World Payment Cards Market Development

George Khetagurov

\section{Abstract}

The article examines the main development trends of the current global market of card payment systems. In particular, it considers the distribution of the market shares of international and local payment systems (in the context of consumer and geographic segments), identifies the main strategic development trends of the payment systems. Summarizing the analysis, the author anticipates the basic parameters for the card industry in the coming years.

На текущем этапе развития глобальной экономики индустрия платежных карт стремительно усиливает свои позиции в большинстве стран мира. Эта тенденция обусловлена свойствами пластиковой карты как платежного инструмента, являющегося в настоящее время наиболее эффективным и безопасным для безналичных расчетов в сфере розничной торговли товарами и услугами. Согласно данным Комитета по 
платежам и рыночным инфраструктурам Банка международных расчетов, на операции по картам в среднем приходится 47,7\% от общего объема безналичных платежей [1]. Пластиковые карты являются наиболее востребованным средством платежа после наличных денег. Таким образом, значимость отрасли платежных карт для современной мировой экономики сложно переоценить, а исследования параметров развития этой отрасли являются весьма актуальными.

Цель настоящего исследования заключается в оценке основных тенденций мирового рынка платежных карт и экстраполировать эти тенденции на ближайшее будущее.

Количественный и качественный анализ основных трендов индустрии платежных карт, выявление основных факторов, влияющих на конъюнктуру, позволят выявить базовые мотивы операторов рынка, оценить их стратегии развития, а также спрогнозировать изменения, которые произойдут на рынке в различных регионах мира в обозримой перспективе.

В ходе исследования автор обращался к различным источникам количественных данных по рынку, которые можно разделить на следующие категории:

1) находящиеся в открытом доступе аналитические отчеты карточных платежных систем;

2) официальные статистические данные центральных банков различных стран и международных организаций, в частности, Комитета по платежам и рыночным инфраструктурам Банка международных расчетов (БМР);

3) статьи в профессиональных периодических изданиях (печатных и электронных);

4) отчеты о маркетинговых исследованиях от специализированных компаний.

Проведем анализ основных показателей и базовых тенденций развития отрасли платежных карт в последние годы. С учетом значительной динамичности отрасли и постоянного появления новых факторов, определяющих ее функционирование (потребительских, технологических, экономических и др.), принято решение уделить особое внимание данным за последний год. Анализ краткосрочной динамики даст возможность более качественно оценить текущие тенденции рынка и определить наиболее перспективные направления его развития.

В отчете The Nilson Report [2] приводятся данные, согласно которым в 2016 г. емкость рынка платежных карт в натуральном выражении составила 15,8 млрд единиц (прирост 9,9\% относительно 2015 г.). Приведенный абсолютный показатель состоит из:

- $\quad$ универсальных карт международных платежных систем (МПС): MasterCard, Visa, American Express, Diners Club, JCВ и UnionPay;

- у универсальных карт локальных платежных систем (Elo, RuPay, Discover, BC, Interac, Star, Bancontact, BCA, BankAxept, PostFinance, girocard, Verve, CuentaRUT и др.);

- предоплаченных, кредитных и дебетовых карт торговых и сервисных предприятий и их сетей. 
Наибольшая доля рынка $(56,11 \%)$ принадлежит универсальным банковским картам международных платежных систем. Доля универсальных карт локальных платежных систем составляет 4,58\%, доля карт торговых и сервисных предприятий $-39,31 \%$.

Данные отчета показывают, что суммарный объем дебетовых, кредитных, и предоплаченных карт МПС в обращении составил на конец 2016 г 8,33 млрд штук (годовой прирост - 13,3\% или 975 млн штук) [3]. Рис. 1 иллюстрирует распределение рыночных долей международных платежных систем.

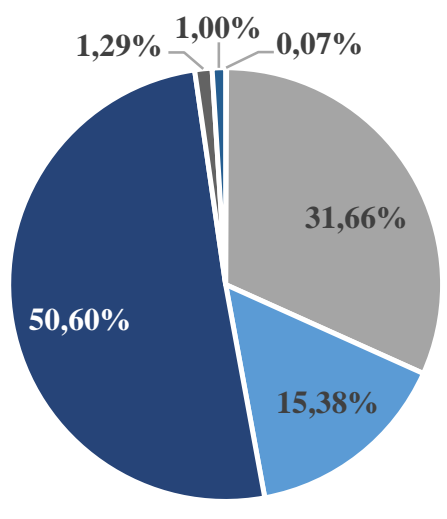

- Diners Club " Visa " MasterCard - UnionPay - American Express JCB

Puc. 1. Распределение рыночных долей МПС (универсальные карты) в 2016 г. Источник: составлено автором по [4]

Китайская система UnionPay стала лидером по количеству эмитированных карт (680 млн штук), за год ее карточная база приросла на 19,2\%. Второе место по объему выпуска - у системы MasterCard (150 млн штук, прирост $13,3 \%)$, третье - y Visa (136,1 млн штук, прирост 5,4\%). Далее идут American Express (4,8 млн штук, прирост 4,7\%) и JCB (4,2 млн штук, прирост 5,2\%). Diners Club стала единственной платежной системой с отрицательным приростом по рассматриваемому показателю $(-0,1$ млн штук или $-1,8 \%$ от существующего количества карт в обращении).

Оценка предложения международных платежных систем в разрезе продуктовых сегментов показывает, что на рынке доминируют дебетовые карты. Их рыночная доля достигла в 2016 г. 73,2\% (в 2015 г. этот показатель составлял 71,31\%). Отметим, что среди МПС такие карты выпускают только MasterCard, Visa и UnionPay. В карточной базе MasterCard дебетовые карты составляют $42,15 \%$, в базе Visa $-65,74 \%$, в базе UnionPay - 90,72\%. Емкость рынка дебетовых карт в течение 2015-2016 гг. выросла на 853,1 млн штук. Для сравнения прирост емкости рынка кредитных карт за это время составил 121,9 млн штук.

В 2017 г. прогнозируется прирост емкости рынка платежных карт на $42,4 \%$. В натуральном выражении объем рынка составит примерно 20,56 млрд. шт. (рис. 2). 


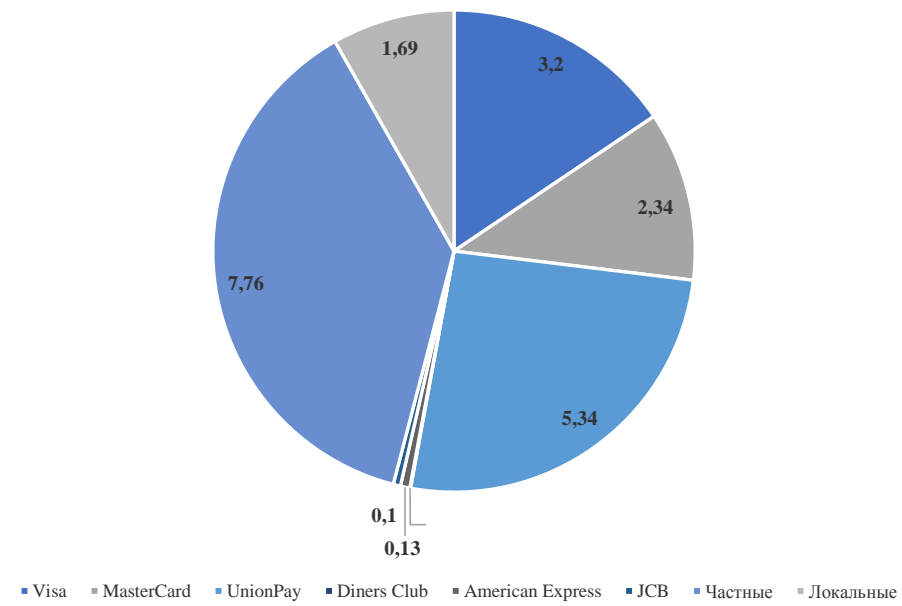

Puc. 2. Прогнозная емкость и структура мирового рынка платежных карт в 2017 г. Источник: составлено автором по [5]

Значительный рост ожидается в сегменте розничных карт, что будет вызвано преимущественно ростом спроса на предоплаченные платежные инструменты со стороны потребителей, стремящихся минимизировать свое взаимодействие с банками. В недавнем прошлом предоплаченные карты эмитировались в относительно небольших количествах. Выпуск осуществлялся исключительно торговыми и сервисными компаниями. В настоящее время такие карты эмитируются также лицензированными банковскими и небанковскими финансовыми компаниями, государственными учреждениями, а также ассоциированными участниками МПС. Примечательно, что часто предоплаченные карточные продукты заполняют те рыночные ниши, в которых выгода и удобство использования других продуктов минимальны.

В США правительства штатов и районные администрации активно внедряют использование предоплаченных карт международных ПС для выплаты пособий. Это позволяет экономить значительные бюджетные средства, так как исчезает необходимость нести расходы на обработку чеков. Такой же подход реализован в Бразилии, Колумбии и Доминиканской Республике. Предоплаченные карты стали популярными в странах Ближнего Востока (Caудовская Аравия, ОАЭ и др.) среди иностранных работников, которые переводят с помощью этих карт деньги семьям за границу [6]. Согласно данным отчетов различных МПС, существует значительный потенциал дальнейшего роста мирового рынка предоплаченных платежных карт.

В отчете The Nilson Report содержатся прогнозные данные, согласно которым в 2017 г. единственной МПС, значительно увеличившей свою долю на рынке платежных карт, станет UnionPay, которая займет четверть рынка (25,98\%). Локальные рынки универсальных платежных карт будут расти преимущественно за счет динамичного развития индийской системы RuPay и бразильской Elo. Ожидается, что за счет роста этих ПС совокупная рыночная доля локальных систем вырастет примерно в два раза. 
Оценка распределение рыночных долей на мировом рынке универсальных платежных карт в динамике показывает, что американские платежные системы стабильно занимают самые высокие позиции (совокупная доля более 90\%). Тем не менее, азиатские конкуренты активно расширяют свой бизнес, что обусловило потерю американскими системами 4,82\% рынка в течение последних пяти лет. Динамика распределения долей карточных систем на мировом рынке по объему платежных операций представлена на рис. 3.

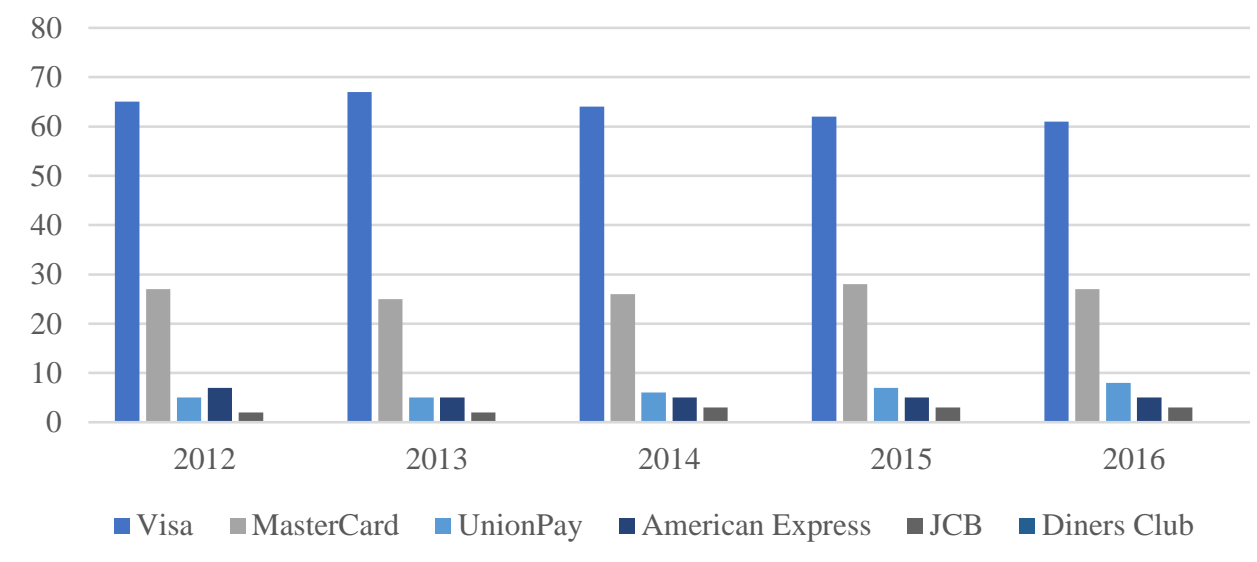

Рис. 3. Доля различных МПС в мировом объеме платежных операций (универсальные карты, \%)

Источник: составлено автором по [7]

Количество стран, в которых выпускаются и обслуживаются платежные карты Visa и MasterCard, значительно больше числа стран, в которых присутствует, например, китайская система UnionPay. Однако, в определенных странах и макрорегионах (например, Юго-Восточная Азия, Ближний Восток, Африканский континент) карты этих МПС составляют менее 50\% в общем обороте. В Юго-Восточной Азии это вызвано, прежде всего, доминированием глобальных операторов UnionPay и JCB, а также активной работой местных карточных ПС, в то время как на Ближнем Востоке и в Африке на рынке лидируют национальные системы платежных карт.

Рост объема платежей, осуществленных на предприятиях торговли и сервиса по картам международных ПС Visa, MasterCard, American Express, UnionPay, JCB и Diners Club в течение 2015-2016 гг. составил 2,786 млрд долл. США (22\%). Объем платежей достиг 15441,68 млрд долл. США. Доля розничных платежей, совершенных с использованием дебетовых и предоплаченных карт, составила 54,37\%. Отметим, что 66,29\% от общей суммы платежей пришлось на карты МПC Visa и MasterCard, однако их рыночная доля снизилась на 5,14\% за год.

В 2016 г. лидером объему платежных операций в денежном выражении стала китайская система UnionPay. Суммарный объем платежей по дебетовым картам этой МПС вырос за год на 49,5\% и составил 3521,15 млрд долл. США, и, таким образом, UnionPay стала лидером по этому показателю. Коли- 
чество осуществленных пользователями данной системы операций составило 9,02 млрд штук (годовой рост 32,2\%). На ближайшие годы прогнозируется сохранение этой тенденции. Из каждых 100 долл. США, использованных в 2016 г. для оплаты товаров и услуг по картам, 59 долл. пришлось на карты Visa и MasterCard, 33 долл. - на карты UnionPay. Данные показатели в 2015 г. составили 65 и 27 долл., соответственно, что еще раз подчеркивает значительный потенциал системы UnionPay. Базовым фактором, определяющим динамичный рост этой МПС, является высокий спрос на ее услуги со стороны различных потребительских сегментов в Китае, подкрепленный активной государственной поддержкой.

Самыми активными держателями платежных карт являются пользователи American Express. В 2016 г. они совершили по каждой карте в среднем 59 платежных операций на общую сумму 8,77 тыс. долл. (табл. 1).

Таблийа 1

Основные характеристики операций по картам, эмитируемым различными МПС

\begin{tabular}{|c|c|c|c|c|c|c|c|}
\hline \multirow{2}{*}{\multicolumn{2}{|c|}{ МПС \категория }} & \multicolumn{2}{|c|}{$\begin{array}{c}\text { Количество платеж- } \\
\text { ных операций на } \\
\text { одну карту }\end{array}$} & \multicolumn{2}{|c|}{$\begin{array}{c}\text { Средняя сумма } \\
\text { одной платежной } \\
\text { операции }\end{array}$} & \multicolumn{2}{|c|}{$\begin{array}{c}\text { Средняя оценка } \\
\text { объема платежных } \\
\text { операций по одной } \\
\text { карте }\end{array}$} \\
\hline & & платежных & uнblx & платежных & uнblx & платежных & uнblx \\
\hline \multirow[t]{2}{*}{ Visa } & $\begin{array}{l}\text { Дебетовые и } \\
\text { предоплаченные }\end{array}$ & 37,27 & 11,45 & $\$ 72$ & $\$ 153$ & $\$ 1749$ & $\begin{array}{c}\$ 1 \\
755 \\
\end{array}$ \\
\hline & Кредитные & 41,29 & 1,35 & $\$ 84$ & $\$ 268$ & $\$ 3463$ & $\$ 363$ \\
\hline \multirow[t]{2}{*}{ MasterCard } & $\begin{array}{l}\text { Дебетовые и } \\
\text { предоплаченные }\end{array}$ & 38,76 & 12,15 & $\$ 65$ & $\$ 134$ & $\$ 1685$ & $\begin{array}{c}\$ 1 \\
633 \\
\end{array}$ \\
\hline & Кредитные & 32,87 & 1,15 & $\$ 85$ & $\$ 270$ & $\$ 2809$ & $\$ 310$ \\
\hline \multirow[t]{2}{*}{ UnionPay } & $\begin{array}{l}\text { Дебетовые и } \\
\text { предоплаченные }\end{array}$ & 1,6 & 0,76 & $\$ 576$ & $\$ 201$ & $\$ 921$ & $\$ 153$ \\
\hline & Кредитные & 17,55 & 0,48 & $\$ 237$ & $\$ 213$ & $\$ 4160$ & $\$ 101$ \\
\hline $\begin{array}{l}\text { AmericanExpre } \\
\text { ss }\end{array}$ & Кредитные & 59,03 & 0,83 & $\$ 149$ & $\$ 135$ & $\$ 8772$ & $\$ 112$ \\
\hline $\mathrm{JCB}$ & Кредитные & 22,74 & 0,49 & $\$ 93$ & $\$ 152$ & $\$ 2117$ & $\$ 75$ \\
\hline DinersClub & Кредитные & 26,8 & 1,41 & $\$ 168$ & $\$ 165$ & $\$ 4505$ & $\$ 232$ \\
\hline
\end{tabular}

Источник: составлено автором по [8]

Доля American Express на мировом рынке является незначительной $(3,75 \%)$, тем не менее, лидерство по интенсивности использования карт свидетельствует о достигнутых этой системой успехах в развитии бизнеса в узкой рыночной нише (премиальные карточные продукты для богатых). Этот и ряд других индикаторов указывают на то, что American Express ориентируется в своей маркетинговой стратегии не на увеличение эмиссии карт (как это делают прочие МПС), а, прежде всего, на всестороннее удовлетворение запросов выбранного сегмента рынка.

Подводя итоги анализа развития мирового рынка платежных карт, можно сделать вывод о росте роли карточной индустрии в системе безналичных расчетов. Население и предприятия розничной торговли заинтересованы в повышении эффективности, экономичности, универсальности и безопасности электронных платежных инструментов, в связи с чем игроки карточного 
рынка регулярно внедряют организационные и технологические инновационные решения, развивают множество проектов, ориентированных на различные рыночные сегменты. Органы государственной власти, как правило, стараются создавать благоприятные условия для развития индустрии платежных карт. Это обусловлено наличием широких возможностей для контроля карточных платежей, удобством налогового учета, прозрачностью платежных операций и рядом других факторов.

В последние годы наблюдалась положительная динамика основных параметров мирового рынка платежных карт, таких как объем выпуска, общая стоимость платежных трансакций, инфраструктурные параметры. Автор прогнозирует сохранение этой тенденции на ближайшее будущее. Наибольшее развитие карточная индустрия получила на рынках США и Западной Европы, характеризующихся высокой популярностью карточных расчетов у населения и высоким уровнем развития платежной инфраструктуры. Однако, происходит постепенная переориентация карточной индустрии в направлении новых рынков (преимущественно азиатских). Снижается зависимость многих стран от американских МПС за счет активного продвижения собственных карточных систем. Лидером в этом отношении является китайская ПС UnionPay, планомерно укрепляющая свои позиции, как в национальном, так и в глобальном масштабе. Наиболее динамично развивающимися рынками карточных расчетов являются Азиатско-Тихоокеанский регион, Латинская Америка, Ближний Восток, Африка и Восточная Европа. Прогнозируется, что в 2017 г. в общей структуре мирового рынка совокупная доля местных платежных систем достигнет 8,26\%. Активная поддержка государственными органами индустрии платежных карт и рост популярности среди работодателей карточных зарплатных проектов стимулируют сдвиг предложения на мировом рынке в сторону дебетовых и предоплаченных карт (и, соответственно, снижается доля кредитных карт).

Одновременно с развитием самого рынка платежных карт развивается платежная инфраструктура. Стабильный рост популярности карточных расчетов в розничной торговле, ужесточение государственного контроля и прочие факторы стимулируют все большее количество торговых и сервисных компаний организовывать прием платежей по картам. Тем не менее, значительная доля держателей карт предпочитает расплачиваться наличными, что обусловливает динамичный рост количества банкоматов и прочих устройств для снятия и приема наличных денег.

\section{Список источников / References}

1. Committee on Payments and Market Infrastructures. Statistic on payment, clearing and settlement systems in the CPMI countries. Figures for 2016 (Preliminary release) Available at: https://www.bis.org/cpmi/publ/d135.pdf

2. The Nilson Report, November 2017, issue 1052.

3. The Nilson Report, March 2017, issue 1037.

4. The Nilson Report, April 2017, issue 1038.

5. The Nilson Report, November 2016, issue 1029. 
6. UnionPay становится крупнейшей платежной системой в мире. [UnionPay stanovitsia krupneishei platezhnoi sistemoi v mire [UnionPay becomes the largest payment system in the world]. Available at: http://www.plusworld.ru/

7. The Nilson Report (Issue 946 | Apr 2013, issue 968 | Mar 2014, issue 992 | Apr 2015, issue 1014 | Mar 2016, issue 1018 | May 2016, issue 1037 | Mar 2017).

\section{Сведения об авторе / About author}

Хетагуров Георгий Валерьевич, кандидат экономических наук, доцент, кафедра «Финансы и кредит», Северо-Кавказский горно-металлургический институт (государственный технологический университет). 362021 Россия, г. Владикавказ. E-mail: gvkhetagurov@ mail.ru

George V. Khetagurov, Candidate of Economic Sciences, Associate Professor, Department of Finance and Credit, North-Caucasian Mining and Metallurgical Institute (State Technical University). Vladikavkaz, Russia 362021.E-mail: gvkhetagurov@mail.ru 